\title{
Tumor treating fields for glioblastoma: Review
}

\author{
Uysal B \\ Gulhane Training and Research Hospital, Department of Radiation Oncology, Ankara, Turkey
}

\begin{abstract}
Tumor treating fields (TTF) is delivered with an original device causing antimitotic activity in tumor cells of glioblastoma patients. Low intensity and intermediate frequency alternating electric fields are effective over metaphase. Tumor treating fields is a novel modality approved by FDA (Federal Drug Association) for newly diagnosed and also recurrent glioblastoma. Frequency of $200 \mathrm{kHz}$ is given with transducer applied on scalp of patient. Phase 3 trial showed the efficacy of this modality alone equivalent compared to chemotherapy. Skin toxicity is the major side effect of this therapy. TTF is now used in recurrent glioblastoma but future perspective shows that this unique modality can be delivered in different solid tumors.
\end{abstract}

\section{Background}

Glioblastoma is the most aggressive and common primary brain tumor in adult population. 18,000 new cases of glioblastoma are diagnosed every year in the United States. Treatment of patients with glioblastoma enrolls chemoradiotherapy and adjuvant chemotherapy for 6-12 months following a maximal surgical resection or a biopsy. Median survival time is approximately 6-7 months and overall survival is 15-16 months in literature. Chemoradiation and surgery techniques have been updated but this doesn't change the prognosis of glioblastoma patients. Firstly, surgery can damage the brain tissue and secondly chemoradiation can be toxic to healthy brain parts.

Neither increasing the dose of temozolomide nor bevacizumab usage had concluded with survival improvement. Tumor Treating Fields (TTF) is a recent and new treatment endamaging tumor cells with low-intensity, intermediate- frequency $(200 \mathrm{kHz})$ alternating electric fields by transducer applied on a scalp. TTF causes apopitosis of tumor cells (Table 1).

\section{Discussion}

TTF is also called as alternating electric fields approved by FDA (federal drug associaton). Skin toxicity is the major adverse effect but not a big issue compared to the toxicities of chemotherapy [1]. TTF was used in newly diagnosed glioblastoma in an article by Zhu et al. quality of life, cognitive and functional status were analyzed in this study. First group was delivered temozolomide and second group got temozolomide and TTF. Second group was better in quality of life for

Table 1. Indications and contrandications of TFF
\begin{tabular}{|l|l|}
\hline Indications & Contraindications \\
\hline $\begin{array}{l}22 \text { years of age or older newly diagnosed } \\
\text { Glioblastoma }\end{array}$ & Deep brain stimulators \\
\hline $\begin{array}{l}\text { Radiological recurrence after receiving } \\
\text { chemotherapy }\end{array}$ & Spinal cord stimulators \\
\hline & Vagus nerve stimulators \\
\hline & Pacemakers \\
\hline & Defibrillators \\
\hline & Programmable shunts \\
\hline & Hydrogel allergy \\
\hline & Skull defects \\
\hline
\end{tabular}

first 9 months and other characterizations for comparative evaluation were similar. TTF group had reported just ithcy skin [2].

FDA approved TTF with its speciality on disrupting mitosis and inhibiting tumor growth over various tumor types in 2011 and 2015. Cell cycle arrest and apopitosis is shown by TTF [3]. Antimitotic activity can be seen between frequencies of $100 \mathrm{kHz}$ and $300 \mathrm{kHz}$ [4].

Novel therapies such as immune modulatory therapies and electrical field treatment seems to improve survival. Future advances in molecular biology and nanotechnology may hopefully give better results for the management of this grad 4 disease [5].

Postacquisition T1 and T2 MRI sequences were anatomically segmented and then solved to determine the distribution of the electric fields and rate of energy deposition at the gross tumor volume (GTV) and other intracranial structures. The main aim is to analyze the physical parameters of TTF. A personalized approach for TTF treatment can be developed when patient and tumor-related factors are associated into the planning [6].

TTF is probably a radiosensitizer when concurrent TTF and RT used together. The removal and replacement of TTF from the scalps of patients daily before and after RT is mostly problematic. Effect of concurrent usage of RT and TTF at the same time was evaluated and it was concluded that more attention is needed for skin toxicities [7].

TTF and chemotherapy combination after recurrence impoved overall survival compared to sole chemotherapy for the globlastoma patients in the EF14 trial [8]. Management of newly diagnosed glioblastoma was discussed in ASCO (American Society of Clinical Oncology) meeting and approved by FDA [9].

TTF is a noninvasive effective and safe procedure that prolonging progression free and overall survival in glioblastoma patients [10].

Correspondence to: Uysal B, Gulhane Training and Research Hospital, Department of Radiation Oncology, Ankara, Turkey. E-mail: drborauysal@ windowslive.com

Received: November 05, 2017; Accepted: November 24, 2017; Published: November 28, 2017 
Technicians, nurses are needed for education on detailed information of TTF usage and the possible complications and also adverse effects of this procedure [11].

Pulsed-dose bevacizumab and TTF was combined for the bevacizumab recurrent glioblastoma patients and the results support TTF and pulsed-dose bevacizumab in an article by Ansstas et al. [12].

Molecular targets of TTF enrolling alfa/beta-tubulin and the septin 2, 6, 7 heterotrimer were evaluated in an article. TTF may trigger antitumor immune response [13].

Maintenance therapy include temozolomide usage for 6 courses after chemoradiotherapy. TTF and temozolomide concomitant usage was compared with temozolomide only and progression-free and overall survival was significantly prolonged [14].

Although glioblastoma is a mortal disease, the efficacy of TTF with other combinations like chemotherapy, immunotherapy and radiotherapy should be supported with novel literature [15]. Potential tumor resistance is a really important topic needed to be researched for these Who Grad 4 dismal tumors [16].

TTF is a novel and promising therapy for glioblastoma patients. However, there is a problematic issue about skin adverse effects. Topical management with corticosteroids or antibiotics prevent skin areas effected from TTF. Quality of life should be maintained when managing this strategy [17].

TTF is evaluated in solid tumor brain metastases, nonsmall cell lung cancer, ovarian and pancreatic cancer with ongoing and future trials. Researchers wait for improving results from these trials same as newly diagnosed or recurrent glioblastoma $[18,19]$.

\section{References}

1. Lok E, Swanson KD, Wong ET (2015) Tumor treating fields Therapy device for glioblastoma: physics and clinical practice considerations. Expert Rev Med Devices 12: 717-726. [Crossref]

2. Zhu JJ, Demireva P, Kanner AA (2017) Health-related quality of life, cognitive screening, ad functional status in a randomised phase 3 trial (EF-14) of tumor treating fields with temozolomide compared to temozolomide alone in newly diagnosed glioblastoma. J Neurooncol 135: 545-552. [Crossref]

3. Zhu P, Zhu JJ (2017) Tumor treating fields: a novel and effective therapy for glioblastoma: mechanism, efficacy, safety and future perspectives. Chin Clin Oncol 6: 41. [Crossref]
4. Mrugala MM, Ruzevick J, Zlomanczuk P, Lukas RV (2017) Tumor Treating Fields in Neuro-Oncological Practice. Curr Oncol Rep 19: 53. [Crossref]

5. Toms SA, Tapinos N (2017) Recent Advances in the Treatment of Gliomas Comprehensive Brain Tumor Center. $R$ I Med J 100: 43-46. [Crossref]

6. Lok E, San P, Hua V, Phung M, Wong ET (2017) Analysis of physical characteristics of tumor treating fields for human glioblastoma. Cancer Med 6: 1286-1300. [Crossref]

7. Bender E, Kozak K, Howard S, Hayes L, Bayouth J, et al. (2017) The effect of Optune tmor treating fields transducer arrays on skin radiation dose during radiotherapy. J Clin Neurosci 42: 172-175. [Crossref]

8. Kesari S, Ram Z (2017) Tumor treating fields plus chemotherapy versus chemotherapy alone for glioblastoma at first recurrence: a post hoc analysis of the EF-14 trial. CNS Oncol 6: 185-193. [Crossref]

9. Mehta M, Wen P, Nishikawa R, Reardon D, Peters K (2017) Critical review of the addition of tumor treating fields (TTFields) to the existing standard car efor newly diagnosed glioblastoma patients. Crit Rev Oncol Hematol 111: 60-65. [Crossref]

10. Saria MG, Kesari S (2016) Efficacy and Safety of Treating Glioblastoma With TumorTreating Fields Therapy. Clin J Oncol Nurs 20: S9-9S13. [Crossref]

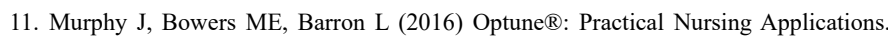
Clin J Oncol Nurs 20: S14-19. [Crossref]

12. Ansstas G, Tran DD (2016) Treatment with tumor-treating fields therapy and pulse dose bevacizumab in patients with bevacizumab refractory recurrent glioblastoma: a case series. Case Rep Neurol 8: 1-9. [Crossref]

13. Swanson KD, Lok E, Wong ET (2016) An overview of alternating electric fields therapy (novoTTF therapy) for the treatment of malignant glioma. Curr Neurol Neurosci Rep 16: 8. [Crossref]

14. Stupp R, Tallibert S, Kanner AA, Kesari S (2015) Maintenance therapy with tumortreatng fields plus temozolomide vs temozolomide alone for glioblastoma: a randomized clinical trial. JAMA 314: 2535-2543. [Crossref]

15. Wong ET, Lok E, Swanson KD (2015) An evidence-based review of alternating electric fields therapy for malignant gliomas. Curr Treat Options Oncol 16: 40. [Crossref]

16. Rehman AA, Elmore KB, Mattei TA (2015) The effects of alternating electric fields in glioblastoma: current evidence on therapeutic mechanisms and clinical outcomes. Neurosurg Focus 38: 14. [Crossref]

17. Lacouture ME, Davis ME, Elzinga G, Butowski N (2014) Characterization and management of dermatological adverse events with the NovoTTF-100A system, a novel anti-mitotic electric field device for the treatment of recurrent glioblastoma. Semin Oncol 41: 1-14. [Crossref]

18. Davies AM, Weinberg U, Palti Y (2013) Tumor treating fields: a new frontier in cancer therapy. Ann N Y Acad Sci 1291: 86-95. [Crossref]

19. Pless M, Weinberg U (2011) Tumor treating fields: concept, evidence and future. Expert Opin Investig Drugs 20: 1099-1106. [Crossref]

Copyright: (C2017 Uysal B. This is an open-access article distributed under the terms of the Creative Commons Attribution License, which permits unrestricted use, distribution, and reproduction in any medium, provided the original author and source are credited. 